\title{
(Re)constructing Masculinity: Representations of Men and Masculinity in Australian Young Adult Literature
}

\author{
Troy Potter
}

\begin{abstract}
In Masculinities and Identities, David Buchbinder suggests that, socially, the term 'masculinity' is used in such a way that its meaning is 'immutable and permanent in an effort to codify, contain and render fixed a wide spectrum of the continually changing attitudes and practices of real men' (Buchbinder 1994, pp.3-4). By this definition, masculinity is inextricably unstable and anything but homogenous. This perception of masculinity is supported by R.W. Connell, who introduces the phrase 'hegemonic masculinity'. In Masculinities, Connell defines hegemonic masculinity as:
\end{abstract}

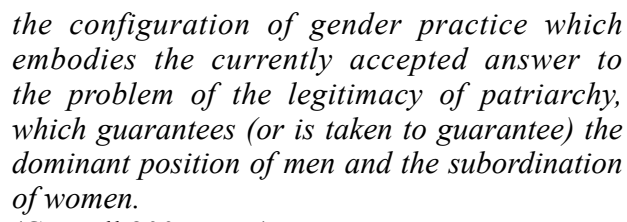

(Connell 2005, p.77)

As a result, among the multiple masculine discourses present within a culture at a particular point in time, 'There are differences and tensions between hegemonic and complicit masculinities, oppositions between hegemonic masculinity and subordinated and marginalised masculinities' (Connell 2005, p.242). Thus, while there is a range of masculinities available for men and boys to adopt, including macho, sensitive, straight, gay and New Age, to name a few, only one of these configurations can occupy the hegemonic space.

In this essay, I analyse how the representation of masculine discourses, and the dialogic processes at work between those present (or absent) function to support, to undermine or to challenge the current hegemonic masculinity in two Australian Young Adult realist texts, David Metzenthen's Boys of Blood and Bone (2004) and Scot Gardner's Burning Eddy (2003). While various and viable masculine schemata, and the dialectical relations between them, may exist in society and be represented within a text, I argue that the masculine constructions which are represented and privileged in the chosen two texts ultimately perpetuate and support normative hegemonic masculinity, that is, masculinity which can be characterised by heterosexuality, a desire for mateship, a sense of responsibility or duty, actual or implicit misogyny, and an inability or unwillingness to express emotion and taciturnity (Romøren and Stephens 2002, p.220).

Literature is of significant cultural importance in reaffirming or challenging cultural ideologies, including those of gender and masculinity. As Buchbinder argues, cultural texts 'reflect models and ideologies abroad in the culture, and ... reinforce them and refract them back into the culture' (Buchbinder 1994, p.74). In addition to this, Buchbinder argues that repeated representations will become naturalised, with any criticism of these representations deflated and, potentially, absent (Buchbinder 1994, p.74). While Buchbinder does not specifically analyse the function of Young Adult literature in the representation and reconstruction of masculine ideologies within a culture, I would suggest that Young Adult fiction as a genre perhaps has a particularly significant role in reflecting and refracting ideologies back into the culture in which they are read. This is primarily due to the inherent nature of adolescent fiction, namely as a means for adults to represent ways of behaving to the adolescent reader. Tim Prchal notes of children's literature that 'realistic stories of boyhood helped to shape shared conceptions of real boyhood, and these conceptions then became part of a matrix upon which to culturally redefine masculinity' (Prchal 2004, p.203). Kimberly Reynolds has also recognised the significance of children's and Young Adult literature in challenging gendered constructions. She argues that any successful challenge to the polarised construction of masculinity and femininity 'needs to begin in infancy and to be sustained throughout childhood' (Reynolds 2002, p.99). In Young Adult literature, the reader is addressed directly and positioned within the represented ideologies, and thus the potential exists for the reader to adopt those same ideologies. This occurs in Boys of Blood and Bone and Burning Eddy, where the reader is positioned to accept the privileged constructions of masculinity as normative.

Australian masculinity is an homogenous construction in Boys of Blood and Bone, one that has remained unchanged throughout the past century. Metzenthen employs a dual narrative structure to parallel the lives of two young Australian men who lived eighty-five years apart: Henry Lyon, an upper-middle class contemporary university student, and Andy Lansell, a country boy who becomes 
an Australian digger and is killed during the First World War. Excerpts from Andy's diary, which Henry obtains when he becomes stuck in the country town of Strattford, separate the two narratives. While in Strattford, Henry befriends Graham and his girlfriend, Janine. It is Janine (who we later discover is Andy's great-granddaughter) who lends Henry the diary of Andy Lansell. Despite Henry's and Andy's class differences, emphasised by the stylistic contrast between the language used by Andy and the soldiers, compared with Henry and his friends, Metzenthen uses the dual narrative structure to construct repeated and parallel story motifs, elements and discursive features, thus positioning the reader within an unchanging and essentialised masculine discourse.

The polemic representation of the past further situates the reader within the ideologies which are represented to them. Henry's attainment of adulthood is dependent on his understanding of the past and, from the beginning of the novel, the reader is invited to accept what is being represented to them:

But seen or unseen, it's possible for our paths to cross with those who have lived before - and sometimes we meet them, in a way. And the people who once lived, who were as real as we are now, have much to tell to those who listen. And Henry Lyon was always prepared to listen.

(Metzenthen 2004, Prologue)

The reader has access to the past through both literal and metaphorical means: the reader travels with Henry through the old country town, Strattford, and later to the war graves in France, and he/she 'travels' through Andy's diary. The reader has further access to the past through the third person narration of Andy's experiences during World War I. There is an androcentric bias, though, to the interpellation of the reader and the importance of the past in the development of contemporary Australian subjectivities. It is Henry, not Janine, despite her familial connection with Andy, who achieves a deeper understanding of the past and develops his Australian identity by reading the diary and visiting the war graves. Further, Henry is the one who readily understands and accepts the dialect of Andy's diary, simultaneously orientating the focus of the text towards the masculine and normalising the represented masculine discourses represented to the reader.

The verisimilitude of Andy's diary, reminiscent of actual war diaries from the World Wars, exposes the extent of hegemony at work during the first half of the twentieth century and within the text. The only reason Andy uses the diary, a traditional feminine writing form, is because his girlfriend, Cecelia, gave it to him. In addition to this justification, the diary is masculinised - the entries are short and emotionally evasive, lacking self-reflection - further distancing the feminine from the masculine construction in the text. Henry's justification of Andy's taciturn diary entries positions the reader to accept the masculine ideologies represented to him/her and also to consider that masculine discourses have remained unchanged throughout the past century.

Both then and now, it seems that there is no alternative but to subscribe to society's expectations of men, regardless of any conflicting personal desires they my have. This is evident in the twentieth century, when Andy lacks agency in his decision to go to war:

It was all pretty much inevitable though, he figured. From that first morning the boys went ashore against the Turks, the pressure to join up was like a steady wind that swept across the paddocks, across the school yards, up every street in every town, and in through the front door of every pub. You boys have gotta go, you boys have gotta go. And under their breath they had murmured, 'Yeah, yeah, we bloody know.'

(p.63)

While Henry attempts to mollify this sense of powerlessness by suggesting that the men had to 'take what was happening to [them] and deal with it according to [their] own rules' (p.118), subscribing to the hegemonic masculine discourse is ultimately an act of relinquishing agency, an act which is normalised in Boys of Blood and Bone. Presented to the reader as an heroic act, Andy's movement towards the frontline, symbolic of his journey from boyhood to manhood, is actually a disempowering process, one through which Andy loses his innocence and his sense of self. The 'war controlled everything' (p.231); it is 'a vacuum that 
took hope as well as life, and in its place left knowledge that was filthy and foul, and that would always be filthy and foul' (p.204). Andy's memories of the farm, of his home, begin to fade 'and there was nothing he could do about it' (p.94).

It has been argued that, in Australian literature, the digger is 'depicted not as a larger-than-life hero going into battle but as a very human survivor reflecting on the meaning of it all' (Rickard 1988, p.71). The same effect is true of Boys of Blood and Bone. The title sets up this construction, as it implies that the soldiers are, very much, human and vulnerable. Furthermore, the reader is witness to Andy's conflicting reflections on the war and his need to kill. However, Andy is not reintegrated into Australian society. Rather, he is killed during the war. While this may be reflective of the inability or difficulty of reintegrating war heroes into society, I argue that Andy's death allows him to be literally transformed into an heroic and mythic masculine figure whom the reader should respect and emulate. This construction is reminiscent of David Buchbinder's characterisation of the soldier, one of the normative masculinities seen in Australian culture, as 'stoic, bearing their agony discretely, dismissing mortal wounds as mere scratches, and thinking of others - family, girlfriend, home, another soldier - rather than themselves' (Buchbinder 1994, p.75). Reaffirming this construction, Andy upon his death, only experiences 'the love of the boys, his parents, his sister, his grandparents, Cecelia and Frances-Jane, and ... his baby' (p.277).

While the idealisation of Andy's life (and death) provides the reader with an Australian masculine role model, there is an absence of femininity in the novel, which reinforces the oppositional relationship between masculinity and femininity. Already I have mentioned the implicit exclusion of women in relation to the past. This exclusion becomes outright misogyny when women are represented as either sexual, and thus a threat to masculinity, or virginal, and thus requiring protection. In the twentieth century, Andy is troubled by his feelings for his virginal girlfriend, Cecelia, and the woman he had a tryst with, the sexual Frances-Jane. When Andy discovers that his liaison with Frances-Jane resulted in a pregnancy, he initially wishes that Frances-Jane would take off, thus protecting himself and Cecelia from any backlash. However, because of his sense of duty, this time to a woman, Andy accepts that he is honour-bound to marry Frances-Jane, despite his feelings for Cecelia. In the twenty-first century, women are represented in a similar manner. Henry is troubled by his desire to end his relationship with Marcelle and to act on his feelings for Janine. Henry's desire to protect Marcelle prevents him from ending their relationship. Instead, it is Marcelle who must end it but, in doing so, she causes Henry to feel 'weak and devious' (p.127). At the end of the novel, Henry's inaction, this time as a result of his perceived need to honour Janine's dead boyfriend, forces Janine to become the agent and ask Henry to kiss her.

As with the feminine constructions, sexual intercourse is dichotomised in Boys of Blood and Bone. During the war, non-procreative sex with prostitutes provides the soldiers with an escape from the atrocities of the war, helping them to feel 'safe and alive' (p.224). Through his experiences of the war and in London, Andy realises that 'guilt over sex was not something he was prepared to devote much time to any more' (p.229). Ironically, Andy initially agonises over his procreative sexual experience with Frances-Jane. Rather than dismissing the situation as a tryst, Andy begins to perceive the expected baby and his resultant fatherhood as providing him with a meaning for the war. This suggests to the reader that procreative sex is of more significance than non-procreative sex. Further, Andy's inevitable fatherhood simultaneously demonstrates the traditional male view of power, patriarchy and continuity inherent in procreation. As one of Andy's mates says of fatherhood, 'I don't give a fuck what anybody back home says, mate. It's the best thing any of us 'ave ever done and might ever do' (p.200). To ensure that no ambiguity remains as to the importance of fatherhood, Janine, Andy's great-granddaughter, returns to Andy his diary and, metaphorically, his identity at the end of the novel.

Metzenthen's novel reasserts traditional notions of Australian masculinity; his novel is a book for Boys of Blood and Bone, a do-it-yourself guide to Australian masculinity. Embedded within, and reflecting, Australian culture, it is unsurprising that Metzenthen has chosen to resurrect, arguably simplistically as a cultural device, the digger as the ideal of Australian masculinity, displaying such qualities 
as selflessness, respect for duty and camaraderie. However, in doing so, Metzenthen fails to represent alternative masculinities and reawakens the oppositional relationship between masculinity and femininity. In addition, the reader, like Henry and Andy, is positioned to accept and to subscribe to Metzenthen's idealised representation of Australian masculinity.

Unlike Metzenthen's Boys of Blood and Bone, which perpetuates traditional Australian masculinity, Scot Gardner's Burning Eddy critiques hegemonic Australian masculinity and presents to the reader an alternative masculinity through the empowerment of the narrator and main protagonist, fifteen-year-old Daniel Fairbrother. Daniel is an example of what Buchbinder calls a New Age Man, a man who is:

more in harmony with the earth and with nature, less convinced of the authority and rightness of traditional male logic, and more amenable to alternative ways of thinking. He attempts to get in touch with his feelings, and is willing to make himself vulnerable, emotionally, to others.

(Buchbinder 1994, p.2)

While it is these qualities of the New Age Man schema which initially cause Daniel's alienated subject position (he has no friends and is assigned the derogative nickname 'Fairy', connoting homosexuality and a love of nature ), it is Daniel's compassion, self-reflection and willingness to consider alternative ways of thinking that enable him to develop his self-awareness and agency. Thus, as Stephens argues, the New Age Boy masculine schema is preferable to the reader, as the New Age Boy's masculinity is defined 'as the attainment or disclosure of an element of selfawareness which enables him both to take responsibility for his own life and to take on significant social contributions' (Stephens 2002, p.38).

The first-person narration of Burning Eddy allows the reader to experience and to empathise with Daniel's isolation and confusion. This is most clearly demonstrated by an episode in the forest, when Daniel spies on some boys. The reader experiences Daniel's pain and alienation when his subordinate position is uncovered. He is hunted by the boys, 'like a rabbit in a spotlight' (Gardner 2003, p.43), thrown to the ground and beaten. Daniel confides his dislocated subject position to the reader, admitting that he 'didn't have a life. No friends, a messed up family, no hobbies, no sports, no interests. No life' (p.44). While the reader is positioned to critique the masculinity which the boys represent, Daniel's confession that he wished he 'could have walked up and knocked on the wall of the shack' (p.48) suggests that there is no alternative for Daniel but to be accepted into the masculine discourse previously challenged and, subsequently, reaffirms to the reader the extent of hegemony at work in society.

Before an alternative masculinity can be offered, the hegemonic Australian masculine schema must be undermined. This is achieved primarily through the negative representation of the men who subscribe to it, particularly Daniel's father, Stephen.

As in Boys of Blood and Bone, fatherhood is a respected subject position within the masculine hierarchy represented in Burning Eddy. However, Stephen is constructed as an inadequate father: he is often absent and, when present, is potentially violent. While Stephen's absence is initially voluntary, evidenced by his 'locks on everything' (p.24), it becomes imposed at the end of the novel when he is imprisoned. Whether voluntary or enforced, Stephen's absence impacts little on the operation of the family unit. If anything, Stephen's prolonged absence enables the family to grow and experience a greater sense of freedom, further suggesting to the reader that the masculine position Stephen occupies is redundant and restrictive.

While arguably it is the responsibility of the father to assist his son to develop a male identity, to provide his son with a role model and to initiate him into manhood (Horrocks 1994, p.77), Stephen is unable to fulfil this function for Daniel. Instead, someone other must assist Daniel to develop his (variant) masculinity. This other is Eddy, an eighty-six-year-old woman. Unlike Stephen, Eddy is constructed as a transgressive figure and, like Daniel, occupies multiple subject positions (she is a wise crone, a widow and a lover). While she is slightly masculinised (she makes music with her farts and has a tattoo), Eddy is represented as the grandmother weaver, imagery which 
invites the reader to accept Eddy as an appropriate role model for Daniel.

Daniel's and Eddy's student-mentor relationship is reminiscent of Wilbur's and Charlotte's relationship in E. B. White's Charlotte's Web (1952). McGillis suggests of Charlotte's Web, 'The web itself ... signifies both death and life, connectedness and separation' (McGillis 1996, p.55). The web motif in Burning Eddy functions in a similar manner. At the beginning of the text, Daniel informs the reader that the spider is 'the grandmother weaver; always patient and watchful, responsible for the construction and maintenance of the web of life' (p.6). Eddy teaches Daniel about life and death just as Charlotte teaches Wilbur. And, just as Wilbur is taught to 'take on a position of authority and responsibility, and to accept life's fullness - the glory of life and death' (McGillis 1996, p.58), Daniel, too, learns to accept the complexity and fullness of life. When Daniel scatters Eddy's ashes at the end of the novel, he notices that Eddy literally becomes 'The web of life' (p.214). Daniel's realisation signifies his movement from the disempowered child who was moved to the country by his family, to a young adult who is preparing to take control of his life. In the final chapter, 'Eagle', connoting flight and freedom, Daniel affirms, 'I decided to take my life into my own hands' (p.217).

The attainment of agency and intersubjectivity is inextricably linked with openness and compassion in Burning Eddy, as these two characteristics allow successful relationships, and therefore agency, to be developed. This concept is presented to the reader through reference to secrets and forgiveness, metaphors for isolation and inclusion, respectively. The lesson is simple: by keeping secrets, by keeping part of one's identity hidden, an individual is unable to form interrelationships and therefore cannot acquire subjectivity and agency. As Eddy warns, 'you can only know someone as much as they want to reveal' (p.125). The juxtaposition of Stephen and Eddy, two conversely opposed ways of being, positions the reader to reject emotional isolation and silence, which is a requirement of hegemonic masculinity, and to accept Gardner's revised masculine schema, which encourages a willingness to share part of one's self with others.
The secret which is used to illustrate this point to the reader is that both Stephen and Eddy were victims of sexual assault: Eddy was raped as an adult and Stephen was sexually molested as a child. However, it is only Eddy who readily shares her secret and chooses to forgive the male transgressor:

'What [the rapist] did to me was horrible but to hate a man was to invite hate into my life. So I shouted, "I forgive you, I forgive you" with the rain wet in my hair.'

(p.137)

Eddy's forgiveness, while idealised, demonstrates to both Daniel and the reader that forgiveness prevents one from harbouring negative emotions and, therefore, allows one to develop successful, loving relationships with others. Stephen, on the other hand, is unable to forgive the man who molested him as a child and, when the opportunity arose, chose to murder his molester. While both Eddy and Stephen occupied disempowered subject positions when they were molested, female and child respectively, Stephen was doubly disempowered; he was disempowered as a victim and he was emasculated by the rape. It is Stephen's emasculation which prevents him from informing others of his rape, as this would further displace him within his own conception of the prevailing masculine hierarchy. It appears that Stephen's only recourse is to keep his molestation secret and, when/if it is possible, to reassert his masculinity and masculine dominance over his molester through an act of aggression. While this destructive and purgative act may reassert Stephen's masculinity within a traditional conceptualisation, Stephen's silence paradoxically lowers his position within the masculine hierarchy advocated by Gardner, as his silence alienates him from his family and diminishes his ability to function as a father. Further, Stephen is eventually arrested for the murder, which suggests to the reader that the traditional hegemonic masculine discourse should be removed from society.

While Gardner advocates openness, one's openness must be voluntary. After Stephen is arrested, Daniel has the opportunity to break into his father's shed, an iconic masculine space. Thinking to uncover deep, dark secrets, 
Daniel is surprised by the orderliness of the shed and by the family photos Stephen keeps in his locked drawer, yet another reminder of the barriers Stephen has erected between himself and his family. Daniel leaves the drawer unlocked, perhaps indicating his hope that his father will now 'unlock' himself. No such thing happens. Upon discovering that his masculine space has been violated (in many ways, a repetition of his body being violated by his molester), Stephen reverts to violence to reassert his masculine dominance and to punish the perpetrator, this time his son, Daniel:

\section{'What are you doing going through my stuff?' \\ He kicked me in the guts. If I had been a football I would have flown fifty metres. I'm not a football. The air rushed from me in a wheeze. Something from my guts was forced into my mouth. Bitter like vomit.}

(p.140)

The reader, witnessing this act of aggression, is invited to empathise with Daniel and, thus, to further critique the hegemonic masculinity which Stephen represents and subscribes to. It is only when Stephen begins to exhibit characteristics of Gardner's privileged masculine schema, by sharing the secret of his molestation with Daniel, and later his wife, that understanding, forgiveness and healing can occur.

Daniel, too, must learn to share a secret if he is to move successfully from alienation towards intersubjectivity. When Daniel was in Grade 6, he found his friend, Chris, dead, floating face down in a dam. Daniel became mentally paralysed by the sight and has been unable, since, to communicate his feelings and thoughts about Chris's death. As with his father, Daniel's alienation is contributed to his silence on the matter and his emotional exclusion of others, characteristic of the traditional male schema. Despite Daniel's assertion that he 'didn't want any more secrets' (p.183), and that communication and the expression of emotions are supported in the privileged construction of masculinity in Burning Eddy, limitations are still placed on where and when boys can express their emotions, reminiscent of the constraints Andy is subject to in Boys of Blood and Bone. It is only during an emotional breakdown that Daniel is able to recount the secret of Chris's death to the reader. This inability or unwillingness to express emotions in front of others is again seen at Eddy's funeral. Even though Daniel acknowledges that if he cried, 'no one would really care' (p.195), he does not. Thus, rather than liberating boys and men from the emotional restrictions placed on them by hegemonic masculine discourses, Gardner reinforces them.

This strand of hegemonic masculinity becomes more prominent at the end of the novel when Daniel's attainment of agency is shown to be largely dependent on aspects of traditional Australian masculinity. In an act of rebellion (typically a characteristic of the normative hegemonic masculinity), Daniel enters the masculine space of the shed in the forest from which he was previously excluded. Michael, one of the boys who had beaten Daniel earlier for spying, finds Daniel there. Rather than leaving, Daniel returns to Michael the latter's pocketknife, which Daniel had found in the forest. This begins a dialogue between the two boys, and they discover that both of their fathers are imprisoned (Michael's father, the captain of the CFA, is discovered to be an arsonist, lighting fires to affirm his importance and therefore masculine status; another male whose subscription to the traditional masculine discourse results in his involuntary removal from society). Daniel's initiation into the hegemonic masculine discourse is formalised when the boys share a beer and Michael renames Daniel from 'Fairy' to 'Dan'. This reaffirms to the reader that 'it is other men who confer [a boy's masculinity] upon him' (Buchbinder 1994, p.35), despite the previous importance of Eddy, and the feminine, in developing a (variant) masculinity. Any lingering doubts about Daniel's place within the hegemonic masculine discourse are eradicated by his developing heterosexual relationship with his girlfriend, Chantelle.

At a superficial level, it appears that Gardner reconfigures Australian masculinity within a fundamentally traditional, heterosexual social framework. Daniel's eventual attainment of agency privileges an alternative masculinity to the reader, one that is a hybrid of masculine and feminine traits, situated somewhere between the exclusive, selfinterested and monologic masculinity of Daniel's father, Stephen, and the inclusive, empathetic and dialogic 
(masculinised) femininity of Eddy. However, the movement towards closure in Burning Eddy ultimately reaffirms traditional Australian masculine discourses. Masculinity and femininity are still constructed as relational concepts, as seen by the juxtaposition of Stephen and Eddy, which maintains the binary relationship between masculinity and femininity and the subsequent patriarchy this produces. Furthermore, the preferred masculinity offered to the reader still subordinates variant, but nonetheless valid, masculinities: the traditional Australian masculinity is now subordinated, while the possibility of homosexuality is still excluded.

Both Boys of Blood and Bone and Burning Eddy represent the development of a male adolescent protagonist's subjectivity and masculinity within a contemporary Australian context. The male protagonists must define their own subjectivity against the traditional, hegemonic Australian masculinity represented in the text. While both texts set up similar constructions of hegemonic masculinity, the treatments of it are vastly different. Boys of Blood and Bone reaffirms the hegemonic masculinity by using the past to reinscribe, and ultimately to essentialise, traditional and mythical constructions of Australian masculinity. Variant masculinities are excluded from the text and the reader is presented with, and positioned within, an exclusively monologic masculine discourse. While Burning Eddy attempts to present to the reader an alternative construction of masculinity, the reconceptualisation is unsuccessful as the revised masculine schema which is privileged is still dependent upon characteristics present in traditional constructions of Australian masculinity.

Further, the interpellation of the reader within the represented masculine ideologies is problematic, as the movement towards closure in both texts is ultimately a reinstatement of a hierarchy of masculinities, and thus a movement towards monologism. At its worst, this closure is a movement towards total monologism. Boys of Blood and Bone is an example of this. All masculine discourses and ideologies, save for those championed by the author, are excluded from the text and thus variant and viable masculinities which are present in the society at large are discounted. At best, the movement towards closure reinstates a hierarchy of masculine discourses with a specific masculine schema being privileged over inferior ones, maintaining the dialectical processes at work between masculine discourses, as seen in Burning Eddy. Yet, despite the extent of monologism in either text, it appears that masculinity, whether traditional or variant, is unavoidably constructed in opposition to femininity, Thus, patriarchal systems and the subordination of women are maintained.

While a range of masculinities is represented in contemporary Australian Young Adult fiction, these representations are still constrained by elements of the normative and, to some extent, mythic Australian masculinity, namely a desire for mateship, an inability to express emotions and the exclusion of homosexuality. Why it should be so difficult for writers of adolescent realist fiction to reconfigure masculinity is suggested in part by Pennell, who argues:

Changing gender representation in narratives is not
a simple matter of reformulating gender attributes
or actions, because traditional social relations and
structures can be reinstated by aspects of narrative
such as language and genre conventions.
(Pennell 2001, p.7)

Thus, Gardner's reconstruction of Australian masculinity does not successfully reconfigure Australian masculinity; it is incumbent upon Daniel to enter into the hegemonic masculine discourse if he is to achieve personal empowerment, as demonstrated by his burgeoning friendship with Michael. For Gardner's alternative masculine schema to be sustained, perhaps Daniel's empowerment needed to be independent of the hegemonic masculine discourse.

As Young Adult realist literature is both a reflection of and a semiotic construal of culture and society, the protagonist must, arguably, be situated within a culturally real setting, one that is recognisable to the reader and can be accepted as a reflection of reality. As a result, the prevalent patriarchal and hegemonic discourses within society are being written into Young Adult realist literature. Add to this the predominantly conservative nature of Children's and Young Adult literature and it seems nearly impossible for an author to rewrite and reformulate hegemonic gender discourses. However, literature should 
not just simply be mimesis. Rather, Young Adult literature should reflect and extend upon the challenge to gender configuration which is seen in society, thus redefining and repositioning masculine and feminine spaces. While Daniel is still constrained by aspects of traditional Australian masculine discourses in Burning Eddy, Gardner's hybridisation of the masculine and the feminine is, perhaps, the beginning of the challenge to traditional masculine discourses in Australian Young Adult literature.

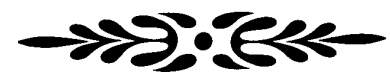

\section{REFERENCES}

Buchbinder, David (1994) Masculinities and Identities. Melbourne, Melbourne University Press.

Connell, R.W. (2005) Masculinities (Second Edition). Crows Nest, Allen \& Unwin

Gardner, Scot (2003) Burning Eddy. Sydney, Pan Macmillan.

Horrocks, Roger (1994) Masculinity in Crisis: Myths, Fantasies and Realities. New York, St Martin's Press.

McGillis, Roderick (1996) The Nimble Reader: Literary Theory and Children's Literature. New York and London, Twayne Publishers.

Metzenthen, David (2004) Boys of Blood and Bone. Camberwell, Penguin.

Pennell, Beverley (2001) 'Shifting Versions of Masculinity in Australian Children's Literature, 1953-1997', Bookbird 39.2: 6-11.

Prchal, Tim (2004) 'The Bad Boys and the New Man: The Role of Tom Sawyer and Similar Characters in the Reconstruction of Masculinity', American Literary Realism 36.3: 187-205.
Reynolds, Kimberley (2002) 'Come Lads and Ladettes: Gendering Bodies and Gendering Behaviors', in John Stephens (ed) Ways of Being Male: Representing Masculinities in Children's Literature and Film. New York, Routledge.

Rikard, John (1988) Australia: A Cultural History. Melbourne, Longman Cheshire.

Romøren, Rolf and John Stephens (2002) 'Representing Masculinities in Norwegian and Australian Young Adult Fiction: A Comparative Study', in John Stephens (ed.) Ways of Being Male: Representing Masculinities in Children's Literature and Film. New York, Routledge.

Stephens, John (2002) "“A Page Just Waiting to Be Written On": Masculinity Schemata and the Dynamics of Subjective Agency in Junior Fiction', in John Stephens (ed) Ways of Being Male: Representing Masculinities in Children's Literature and Film. New York, Routledge.

White, E.B. (1952) Charlotte's Web. London, Hamish Hamilton.

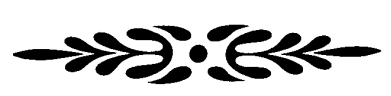

\section{BIOGRAPHICAL NOTE}

Troy Potter is a Science/English teacher at De La Salle College in Melbourne. He is currently completing his $\mathrm{PhD}$ at the Australian Catholic University, focussing on the representation of maternal madness and mental illness in children's literature. 